\title{
Cognitive fluctuations in connection to dysgraphia: a comparison of Alzheimer's disease with dementia Lewy bodies
}

\author{
Emanuela Onofri \\ Marco Mercuri \\ Giuseppe Donato \\ Serafino Ricci \\ Department of Anatomy, Histology, \\ Legal Medicine and Orthopaedics, \\ Sapienza University of Rome, \\ Rome, Italy
}

This article was published in the following Dove Press journal:

Clinical Interventions in Aging

26 March 2015

Number of times this article has been viewed
Background: The purpose of the present study was to examine the relationship between cognitive impairment and the performance of handwritten scripts presented as "letter-writing" to a close relative by patients with dementia Lewy bodies (DLB), as fluctuations of the symptoms phase, and in a matched group of patients with Alzheimer's disease (AD). The degree of writing disability and personal, spatial, and temporal orientation was compared in these two groups.

Design and methods: Fourteen simple questions, designed in a form that could be utilized by any general practitioner in order to document the level of cognitive functioning of each patient, were presented to $30 \mathrm{AD}$ patients and $26 \mathrm{DLB}$ patients. The initial cognition test was designated PQ1. The patients were examined on tests of letter-writing ability. Directly after the letter-writing, the list of 14 questions presented in PQ1 was presented again in a repeated procedure that was designated PQ2. The difference between these two measures (PQ1 - PQ2) was designated $\mathrm{D} \Delta$. This test of letter-writing ability and cognitive performance was administered over 19 days.

Results: Several markedly strong relationships between dysgraphia and several measures of cognitive performance in AD patients and DLB patients were observed, but the deterioration of performance from PQ1 to PQ2 over all test days were markedly significant in AD patients and not significant in DLB patients. It is possible that in graphic expression even by patients diagnosed with moderate to relatively severe $\mathrm{AD}$ and DLB there remains some residual capacity for understanding and intention that may be expressed. Furthermore, the deterioration in performance and the differences noted in AD and DLB patients may be due to the different speed at which the process of the protein degradation occurs for functional modification of synapses.

Conclusion: Our method can be used as part of neuropsychological tests to differentiate the diagnosis between AD and DLB.

Keywords: cognition, deficits, correlation, deterioration

\section{Introduction}

In Western industrial nations, Alzheimer's disease (AD) represents the most common form of dementia, ${ }^{1,2}$ at approximately $80 \%,{ }^{3}$ occupying fourth place among the causes of death (after heart disease and circulatory disorders, cancer, and cerebral hemorrhage). Dementia with Lewy bodies (DLB) is the second most common cause of degenerative dementia after AD.

Worldwide there are currently 25 to 35 million individuals with these illnesses, with five to seven million new cases diagnosed each year, or one new case every 7 seconds. ${ }^{4,5}$ According to the World Health Organization it has been estimated that by the year 2050 the number of people presenting with dementia will be 115.4 million. ${ }^{6}$
Correspondence: Emanuela Onofri Department of Anatomy, Histology, Legal Medicine and Orthopaedics, Sapienza University of Rome, Viale Regina Elena 335, Rome 0016I, Italy

Tel +393395007557

Email emanuela.onofri@uniromal.it 
The pathology of dementia is associated with memory loss, loss of orientation, inability to focus attention, and loss of speech. In addition, we notice cognitive fluctuations, defined as spontaneous alterations in cognition, attention, and arousal. Fluctuating confusion, accompanied by disturbances of consciousness, is an important clinical symptom, with a frequency of $80 \%-90 \%$ in $\mathrm{DLB}^{7,8}$ and $20 \%$ in Alzheimer's disease. ${ }^{9}$ In fact, in these patients, cognitive fluctuations and periods of behavioral confusion, inattention, and alternating episodes of lucidity and capable task performance have been described. ${ }^{10}$ McKeith identified the "marked amplitude between best and worst performance" as a distinguishing feature of the fluctuations in cognition and consciousness in DLB, contrasting this with "minor day-to-day variations" that can occur in dementia of any cause. ${ }^{11}$ The term cognitive fluctuation remains elusive despite several attempts to identify, quantify, and assess the phenomenon. ${ }^{12}$

This fact raises an important question: do the fluctuations occurring in $\mathrm{AD}$ patients have a particular quality and specific characteristics different from fluctuations that occur in DLB dementia?

In addition, many authors have observed in patients with AD dementia, a progressive disorganization and degeneration of the various components of handwriting, the diversity and the accuracy of words used, organization, ${ }^{13}$ punctuation, ${ }^{14}$ the production of grammatically incorrect sentences, the length of the sentences, the morphology of the letters, ${ }^{15}$ the amount of written information, ${ }^{16}$ spelling, ${ }^{17}$ and graphic and spatial layout of letters and their arrangement in texts. ${ }^{18}$

We are not aware of research regarding the degeneration of handwriting in DLB patients. The purpose of the present study was to examine the relationship between cognitive impairment and the performance of handwritten scripts presented as "letter-writing" to a close relative by AD patients, as fluctuations of the symptoms phase, and in a matched group of DLB patients.

Also, it is possible that in graphic expression even by patients diagnosed with moderate to relatively severe AD and DLB there remains some residual capacity for understanding and intention that may be expressed. Concurrently, the relationship between measures of functioning, MiniMental State Examination (MMSE), and number of years elapsed since first indication of disorder with dysgraphia and assessments of cognitive performance was assessed (or debut).

\section{Materials and methods}

Fifty-six patients (from the region of Lazio, Italy) were selected to participate in the study: 30 patients presenting $\mathrm{AD}$ and 26 patients presenting DLB. Patients were diagnosed according to the National Institute of Neurological and Communicative Disorders and Stroke and the Alzheimer's Disease and Related Disorders Association ${ }^{19}$ and the Diagnostic and Statistical Manual of Mental Disorders, 4th edition reference.

In addition, a group of 30 younger, less impaired $\mathrm{AD}$ patients (ADli) was included. Patients were excluded if they presented a history of known or suspected cerebrovascular disease, focal neurological signs or brain imaging evidence for alcohol misuse, head trauma, significant psychiatric history preceding the current diagnosis, or any other major physical illness. All of these diagnoses were confirmed and verified by neurologists in the Department of Neurology at the hospital (Gemelli University Polyclinic - service neuropsychology, Roma and the Alzheimer Evaluation Unit ASLRMF and Alzheimer Evaluation Unit ASLRMD); 26 patients were confirmed by the Department of Neurology and Psychiatry, Sapienza Hospital, Rome, Italy, in the Lazio region. Only subjects with the clinical follow-up and complete diagnostic agreement by the three neurologists were included.

A considerable amount of time (regular meetings every second day for 3 months) was invested in each of the patients in order to promote a relationship of trust and understanding, as well as to reduce stress factors ${ }^{20}$ that may affect patients' mood and attentiveness, or, more seriously, induce behaviors that suggest hallucinations or auditory illusions, paranoid delirium, difficulty in recognizing persons, or loss of cognition of time and place. All the procedures were adopted according to discussions and meetings with nearest relatives and caregivers in order to obtain the consent of the patients as well as those of relatives and caregivers (caregivers could be legal representatives) according to the legal practices.

\section{Alzheimer's disease}

For the sixty patients constituting the AD group and ADli, the diagnosis was based on normal or nonspecific electroencephalography and lateral, occipital brain atrophy on magnetic resonance imaging or computed tomography brain scan, with documented progression after serial observations, and on cognitive test procedures and routine blood assays aimed at excluding the presence of other medical conditions associated with other types of dementia. 


\section{Dementia with Lewy bodies}

Twenty-six DLB patients were included in the study. Diagnosis was confirmed using the international consensus guidelines for DLB, revised in 2005. ${ }^{21}$ All patients presented with dementia at the time of their initial evaluation, which usually preceded the onset of motor signs of disorder by $1-2$ years. Some patients exhibited cognitive impairment concomitant with mild extrapyramidal signs, which, however, never reached the criteria levels for the diagnosis of idiopathic Parkinson's disease, and showed no evidence of focal brain lesions on magnetic resonance imaging.

Exclusion criteria were presence of secondary, reversible causes of dementia that were untreated; concomitant neurological or psychiatric illness, substance use and abuse; and history of significant head trauma.

\section{Mini-Mental State Examination}

MMSE presents a brief 30-point questionnaire to screen for cognitive impairment and dementia. ${ }^{22}$ It estimates the severity of disorder and follows the course over time of cognitive changes in an individual, thereby allowing effective monitoring of an individual's response to treatment.

\section{Unified Parkinson's Disease Rating Scale}

The Unified Parkinson's Disease Rating Scale is a rating scale used to follow the longitudinal course of Parkinson's disease. ${ }^{23}$ It is the most commonly used scale in the clinical study of Parkinson's disease and of DLB.

\section{Clinician assessment of fluctuation (CAF)}

CAF is a short scale consisting of a series of screening questions, regarding fluctuating confusion and impaired consciousness during the month prior to the assessment. The frequency and duration of episodes of fluctuating confusion are both rated on a scale of 0-12 (0 representing no fluctuating confusion, 12 representing severe fluctuating confusion). ${ }^{24}$

\section{Cognitive performance assessment Testing material}

A writing pad was used for writing text or drawing figures. Preferably the tablet was vergatina type (flimsy typing paper, tissue type, or absorbent in order to avoid false interpretations of the writings). A ballpoint pen was used throughout. The patients were invited to sit in a comfortable position.
Table I Example scoring list of 14 questions presented to a hypothetical AD patient in PQI phase and PQ2 phase. These are routine questions which a doctor can ask to the patient

\begin{tabular}{ll}
\hline Questions & Score \\
\hline I. What is your name? & $0-3$ \\
2. When were you born? & $0-2$ \\
3. Where were you born? & $0-2$ \\
4. Which city do you live? & $0-1$ \\
5. What is your address? & $0-1$ \\
6. Who are you living with? & $0-1$ \\
7. Have you got children? & $0-1$ \\
8. What are their names? & $0-2$ \\
9. Why are you here? & $0-1$ \\
10. Have you pain? & $0-1$ \\
II. Where have you pain? & $0-1$ \\
12. How did you get here? & $0-1$ \\
13. How much time did you take to get here? & $0-1$ \\
14. What day is today? & $0-2$ \\
\hline
\end{tabular}

Abbreviations: AD, Alzheimer's disease; $\mathrm{PQ}$, cognition test.

\section{Procedure}

In order to test the cognitive performance of $\mathrm{AD}$ patients and DLB patients as well as test their spatial and time orientation and residual capacity, a standard collection of 14 simple questions were presented to the patients (Table 1). The authors have designed and presented these questions in a form that could be utilized by any general practitioner in order to document the level of cognitive functioning of each patient. For each correct answer, one point was attributed in proportion to the difficulty of the question. ${ }^{25}$ The sum of each test session was represented by PQ; the initial session result was designated PQ1. Following this, each patient was then invited to write a letter to a close relative. On consecutive days of testing, patients were invited to write to either the same relative or another one. The letter-writing task was interrupted when it seemed that the text produced by the patient was substantially (pathologically) confused (when the phrase offered no conceptual association with accompanying text although in the presence of otherwise "correct" syntax) and when it had a sudden lack of readability, disjointedness, and incompleteness in meaning, with intrusions, semantic substitutions, alterations in the spatial organization of handwriting, illegible words, incidence of paraphrases, incapacity to form complete sentences, graphemic substitutions (a grapheme is the smallest semantically distinguishing unit in a written language), omissions, and additions. After this, using a chronometer, the number of minutes that had been reached for each single patient was registered and complete sentences were counted (sentences $/$ minutes $=X F$ ). The whole procedure involving the letter-writing graphia task was interrupted after 20 minutes (see Figure 1). 


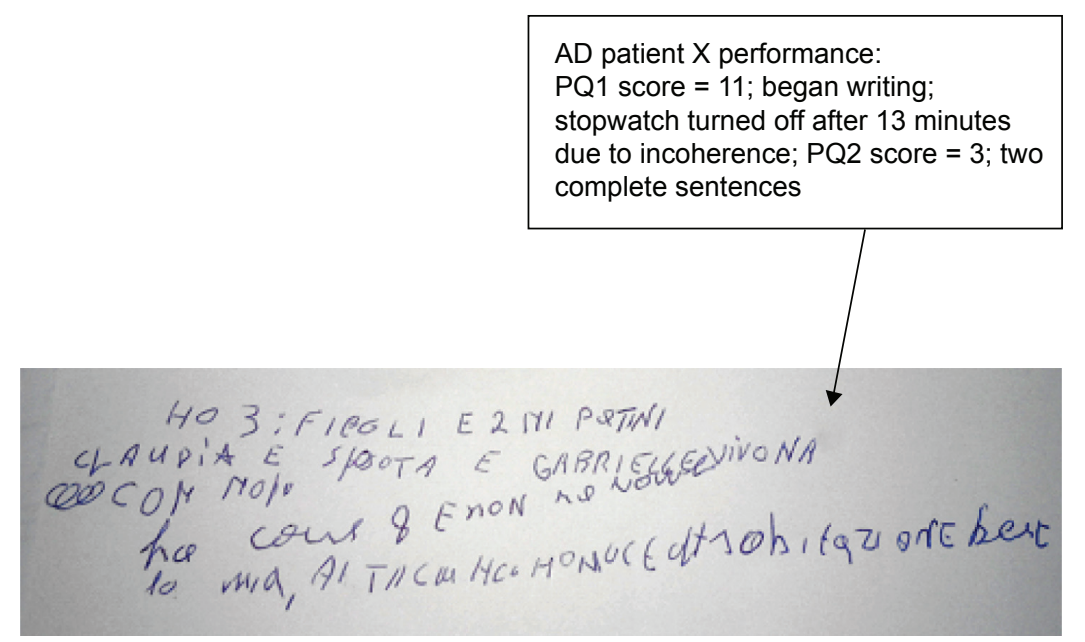

Figure I The performance of AD patient $X$ and DLB patient $X$ during PQI, followed by the letter-writing test, followed by PQ2.

Note: The quality of handwriting, coherence, and comprehension is taken into account before deciding to terminate the writing session. Abbreviations: AD, Alzheimer's disease; DLB, dementia Lewy bodies; PQI, initial cognition test; PQ2, repeated cognition test.

\section{Directly after letter-writing}

The list of 14 questions presented in PQ1 was presented again in a repeated procedure that was designated PQ2. The difference between these two measures (PQ1 - PQ2) was designated $\mathrm{D} \Delta$. These procedures for testing: 14-item test, graphia test, 14-item test were presented in an identical manner every second day over 10 days (days 1, 3, 5, 7, $9,11,13,15,17$, and 19) at the same hour of day on test days in order to hold constant testing procedures over daily curriculum and any clinical interventions that the patients may be subject to.

\section{Statistical analysis}

The results consisting of $\mathrm{PQ} 1$ and $\mathrm{PQ} 2$ scores, $\mathrm{XF}$, and $\mathrm{D} \Delta$ were calculated as means and standard deviations of the $A D$ patient group and the DLB patients over consecutive days of testing. Pearson's correlation coefficient was used to assess the relationship between XF and PQ1 and XF and $\mathrm{D} \Delta$ for both $\mathrm{AD}$ patients and DLB patients for each of the test days. Student's $t$-tests were used to test for pairwise differences for each of the parameters.

\section{Results}

The clinical characteristics of the participants in the study are presented in Table 2.

\section{AD, ADli, and DLB patients: cognitive performance over PQI and PQ2}

The cognitive performance of the AD patients and DLB patients deteriorated from PQ1 to PQ2 (Table 3), with $t$-values reaching significance levels over all 10 days of testing.
The cognitive performance of ADli patients deteriorated from PQ1 to PQ2 (Table 4).

\section{Comparison of AD, ADli with DLB patients: correlation coefficients PQ I versus $\mathrm{XF}$ and $\mathrm{XF}$ versus $\mathrm{D} \Delta$}

The correlation coefficients of both the PQ1 performance and XF relationship and the XF and $\mathrm{D} \Delta$ relationship were all positive and highly significant in $\mathrm{AD}$ patients while they were positive in ADli patients. In DLB patients the correlation coefficient of the $\mathrm{PQ} 1$ performance and XF relationship was positive while the correlation analysis of the $\mathrm{XF}$ and $\mathrm{D} \Delta$ relationship was negative (Tables 3 and 4).

\section{Correlation analyses between functional measures}

Product moment correlations between the functional estimations of MMSE, debut (years), PQ1, D $\Delta$, and PQ2 were

Table 2 Clinical, demographic, and neuropsychological data of the study groups

\begin{tabular}{llll}
\hline & AD & DLB & AD younger \\
\hline Sex (M/F) & $40 \%$ M 60\% F & $46.15 \%$ M 53.85\% F & $35 \%$ M 55\% F \\
Mean age (years) & $83.06 \pm 6.15$ & $78 \pm 6.4$ & $77.4 \pm 5.8$ \\
Educational (years) & $11.0 \pm 3.6$ & $10.3 \pm 2.3$ & $11.3 \pm 2.6$ \\
Debut (years) & $4.43 \pm 1.19$ & $3.3 \pm 0.6$ & $3.4 \pm 1.23$ \\
MMSE & $13.75 \pm 1.96$ & $14.3 \pm 1.5$ & $20.56 \pm 1.6$ \\
UPDRS & 0 & $61.87 \pm 2.5$ & 0 \\
CAF & 2.5 & 6.7 & 0 \\
\hline
\end{tabular}

Notes: Values are reported as mean \pm standard deviation; Debut is defined as number of years elapsed since first indication of disorder.

Abbreviations: AD, Alzheimer's disease; CAF, clinician assessment of fluctuation; DLB, dementia Lewy bodies; F, female; M, male; MMSE, Mini-Mental State Examination; UPDRS, Unified Parkinson's Disease Rating Scale. 


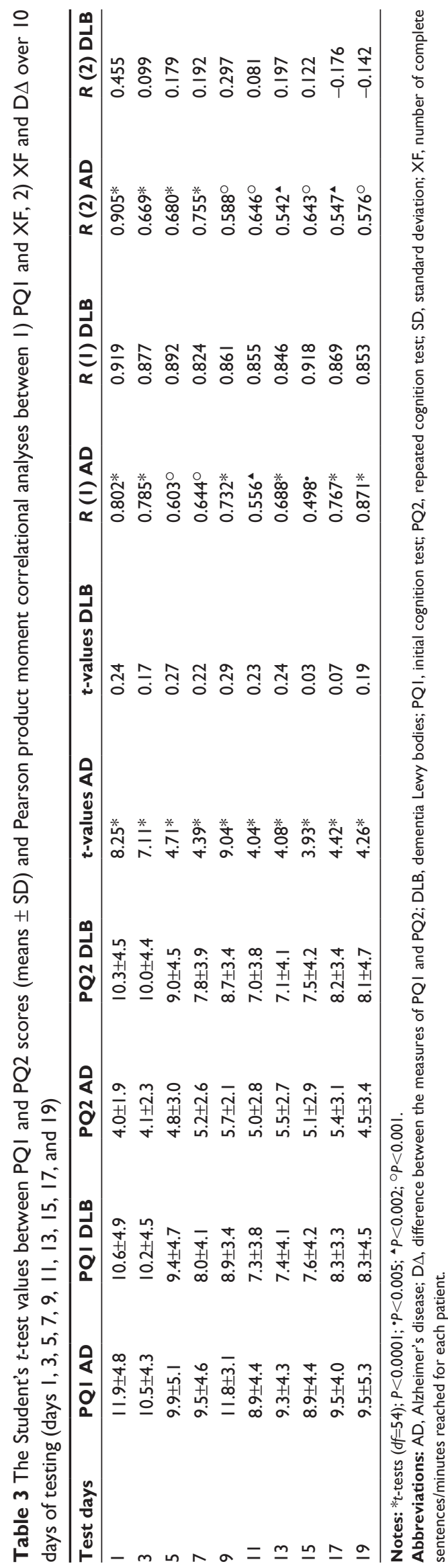

carried out on the data obtained from the $30 \mathrm{AD}$ patients and 26 DLB patients. It was observed that 1) MMSE is correlated significantly with PQ1, XF, and PQ2, 2) MMSE is correlated significantly with $\mathrm{D} \Delta$ in $\mathrm{AD}$ patient while the correlation is negative in DLB patients, and 3) debut (years) does not correlated with $\mathrm{PQ} 1, \mathrm{XF}, \mathrm{PQ} 2$, and $\mathrm{D} \Delta$ in $\mathrm{AD}$ patient while the correlations are not significant in DLB patients (Table 5).

\section{Comparison AD patients with DLB patients}

The cognitive impairment that occurs after the write performance in $\mathrm{AD}$ patients is clearly shown in Figure 2 . The blue plot shows the levels of cognitive impairment that occurred before the writing performance in $\mathrm{AD}$ and $\mathrm{DLB}$ patients (over 10 days of testing) day after day. The red plot emphasizes the cognitive level after the writing test (Figures 2 and 3).

Concurrently, the extent of cognitive performance deterioration; $\mathrm{D} \Delta$ from the 1 st to the 2 nd test was found to be markedly advanced in $\mathrm{AD}$ patients in comparison with the DLB patients (Figure 4).

The extent of dysgraphia by the DLB patients was found to be quite advanced in comparison with the $\mathrm{AD}$ patients (Figure 5).

\section{Discussion}

This study shows the distinctive features of the cognitive impairment in relation to dysgraphia during the cognitive daily fluctuations in DLB patients and in AD patients.

The cognitive impairment, spontaneous alterations in attention, and incoherent speech, alternating with episodes of lucidity and capable task performance are a recognized feature of dementia, especially in DLB, but they are present also in $\mathrm{AD}$.

We examined the relationships between initial cognitive performance (PQ1), the deterioration in cognitive performance following a letter-writing task $(\mathrm{PQ} 1-\mathrm{PQ} 2=\mathrm{D} \Delta)$ and dysgraphia (XF) in a group of $\mathrm{AD}$ patients presenting a moderate to relatively severe stage of disorder, and comparisons with a group of DLB patients and with ADli patients. The results may be summarized as follows: 1) the relationships between initial cognitive performance (PQ1) and extent and dysgraphia over both AD and DLB patients and test days were markedly strong; 2 ) but the deterioration of performance from PQ1 to PQ2 over all test days was markedly significant in AD patients, and it was not significant in DLB patients; 3) the relationships between dysgraphia and cognitive deterioration $(\mathrm{D} \Delta$ ) were also markedly strong in $\mathrm{AD}$ patients, and they were not significant in DLB patients; 
Table 4 Younger, less impaired AD patient Student's $t$-test values between PQI and PQ2 scores (means \pm SD) and Pearson product moment correlational analyses between I) PQI and XF, 2) XF and D $\Delta$ over 10 days of testing (days I, 3, 5, 7, 9, II, I3, I5, I7, and I9)

\begin{tabular}{llllll}
\hline Test days & PQI AD & PQ2 AD & t-values AD & $R(1)$ AD & $R(2)$ AD \\
\hline 1 & $16.0 \pm 2.1$ & $10.3 \pm 1.8$ & 10.92 & $0.578^{\circ}$ & $0.533^{*}$ \\
3 & $15.6 \pm 2.5$ & $9.7 \pm 2.0$ & 10.29 & $0.656^{*}$ & $0.536^{\star}$ \\
5 & $15.3 \pm 2.7$ & $9.7 \pm 1.9$ & 10.28 & $0.616^{*}$ & $0.578^{*}$ \\
7 & $15.3 \pm 2.7$ & $10.0 \pm 1.8$ & 8.84 & $0.689^{\circ}$ & $0.696^{*}$ \\
9 & $15.4 \pm 2.6$ & $10.0 \pm 1.9$ & 8.84 & $0.698^{*}$ & $0.663^{\circ}$ \\
11 & $15.3 \pm 2.7$ & $9.5 \pm 1.7$ & 9.93 & $0.602^{*}$ & $0.536^{\circ}$ \\
13 & $16.9 \pm 2.5$ & $9.4 \pm 1.5$ & 14.81 & $0.657^{*}$ & $0.576^{*}$ \\
15 & $15.3 \pm 2.7$ & $10.0 \pm 1.9$ & 8.84 & $0.603^{\circ}$ & $0.553^{\circ}$ \\
17 & $15.5 \pm 2.7$ & $10.0 \pm 1.8$ & 8.84 & $0.651^{\star}$ & $0.635^{\star}$ \\
19 & $15.4 \pm 2.7$ & $9.8 \pm 1.9$ & 9.45 & $0.695^{*}$ & $0.586^{\circ}$ \\
\hline
\end{tabular}

Notes: $*$ t-tests $(\mathrm{df}=58) ; \mathrm{P}<0.000 \mathrm{I} ;{ }^{\bullet} \mathrm{P}<0.005 ;{ }^{\wedge} \mathrm{P}<0.002 ;{ }^{\circ} \mathrm{P}<0.001$.

Abbreviations: AD, Alzheimer's disease; $D \Delta$, difference between the measures of PQI and PQ2; PQI, initial cognition test; PQ2, repeated cognition test; SD, standard deviation; $\mathrm{XF}$, number of complete sentences/minutes reached for each patient.

4) MMSE correlated significantly with PQ1, PQ2, and with $\mathrm{XF}$ in both groups of patients; furthermore, number of years elapsed since first diagnosis of disorder does not affect the XF (or expression of dysgraphia), PQ1, PQ2, and D $\Delta$. In particular, the nonassociation between MMSE and D $\Delta$ in DLB patients was markedly significant $\left(R^{2}=-0.185\right)$.

Dysgraphia occurs during both the earlier as well as the later stages during the clinical course of $\mathrm{AD}^{26-28}$ and is associated with attentional, motor, and memory deficits that develop during disorder progression. ${ }^{29}$ It has been suggested to be a more sensitive indication of language deficits in AD than anomia. ${ }^{30,31}$ Some author ${ }^{32}$ have observed that the medial walls of the cerebral hemispheres, notably the cingulate gyri, contain species-specific neuron fields that to date are not well known within the scientific community and yet have been implicated as the underlying cause of such varying conditions as dysgraphia and autism in children and obsessive compulsive disorder and $\mathrm{AD}$ in adults. ${ }^{33}$

Table 5 Pearson product moment correlations analyses between MMSE, debut (years), PQI, XF, PQ2, and D $\Delta$ in the 30 AD patients and 26 DLB patients

\begin{tabular}{lll}
\hline & AD patients & DLB patients \\
\hline MMSE - PQI & 0.791 & 0.649 \\
MMSE - XF & 0.790 & 0.601 \\
MMSE - PQ2 & 0.788 & 0.705 \\
MMSE - D $~$ & 0.665 & -0.185 \\
Debut (years) - PQI & -0.632 & 0.382 \\
Debut (years) - XF & -0.584 & 0.288 \\
Debut (years) - PQ2 & -0.604 & 0.169 \\
Debut (years) - D $\Delta$ & -0.554 & 0.037 \\
\hline
\end{tabular}

Note: Debut is defined as number of years elapsed since first indication of disorder. Abbreviations: $A D$, Alzheimer's disease; $D \Delta$, difference between the measures of $\mathrm{PQI}$ and PQ2; DLB, dementia Lewy bodies; MMSE, Mini-Mental State Examination; $P Q 1$, initial cognition test; $P Q 2$, repeated cognition test; XF, number of complete sentences/minutes reached for each patient.
In a sample of 52 Japanese patients presenting mild $\mathrm{AD}$ and 22 healthy controls, writing ability composed of Kana writing-to-dictation and copying Kanji or dictational Kanji and regional cerebral blood flow using single-photon emission computed tomography were studied. ${ }^{34}$ Hayashi et al observed that while Kana writing-to-dictation and copying Kanji were preserved in these AD patients, writing to dictated Kanji words was impaired. The impaired writing of dictated Kanji words was associated with dysfunctional cortical activity, predominantly in the left frontal, parietal, and temporal brain regions, consistent with other Japanese dysgraphia studies. ${ }^{35,36}$

Furthermore, clear differences between $\mathrm{AD}$ patients and healthy control individuals have been found for visuomotor task measures, demonstrating large effect size deficits by $\mathrm{AD}$ patients, especially with visuomotor task progression through its varying conditions..$^{37,38}$ They have observed dysgraphia, primarily dysexecutive agraphia, in patients with frontotemporal dementia and parkinsonism linked to chromosome 17. Patients presenting dysexecutive agraphia show not only difficulties in maintaining the effort inherent to writing but appear to lack the ability to organize their thoughts for expression in written text. They seem to be lacking in the complicated functions underlying writing that encompass narrative coherence, selective attention, planning, etc that are disturbed in executive function impairments.

The present observations of dysgraphia associated with deficits in semantic memory that were exacerbated acutely by the writing task appear to fit current notions pertaining to the progressive performance impairments of $\mathrm{AD}$ patients within language and cognition domains from a staging perspective..$^{39}$

The possible relationships between dysgraphia and the motor functioning domain in $\mathrm{AD}$ has provided novel insights 


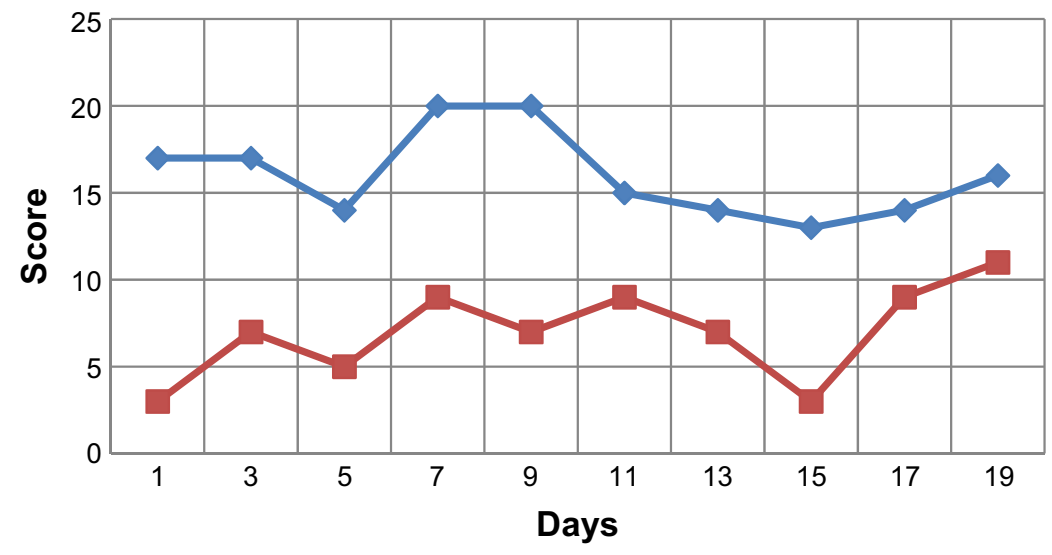

Figure 2 Examples of cognitive impairment: $A D$ patient scores for $\triangle P Q 1$ (before writing) and $\square P Q 2$ (after writing). Abbreviations: AD, Alzheimer's disease; PQI, initial cognition test; PQ2, repeated cognition test.

into the cognitive nature of the disorder ${ }^{40}$ through which mild to moderate stage $\mathrm{AD}$ patients $(\mathrm{n}=59)$ and healthy elderly controls were tested over an extensive assessment of both the central and peripheral components of writing; the former performed less effectively than controls over a broad spectrum of writing measures. Although a predominantly lexical disorder was observed, there were multiple indications of associated disorders located at different stages in the writing/spelling system (eg, phonological route, graphemic buffer, allographic store, graphic motor patterns). The authors concluded that there exists heterogeneous profiles of dysgraphia with primary signs of writing impairment in $\mathrm{AD}$ originating from changes at different points in the brain networks that subserve writing and spelling performance..$^{40}$ In this regard, the possibility of related motor deficits in dysgraphia ought to be considered since there is evidence for altered parietal-motor connections in $\mathrm{AD}{ }^{41}$ It has been found too that sensory-motor plasticity is impaired in the motor cortex of $\mathrm{AD}$ at an early stage of the disease. ${ }^{42}$

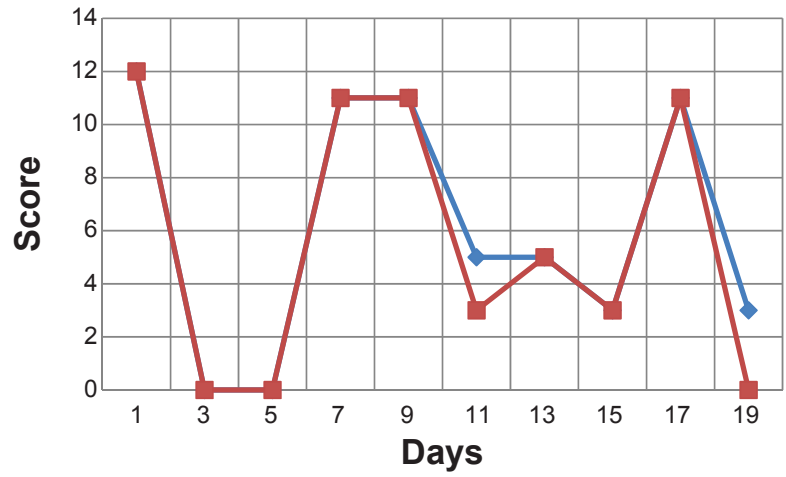

Figure 3 Examples of cognitive impairment: DLB patient scores for $\diamond \mathrm{PQI}$ (before writing) and $\square$ PQ2 (after writing).

Abbreviations: DLB, dementia Lewy bodies; PQI, initial cognition test; PQ2, repeated cognition test.
Several have indicated that agraphia is related to severity of AD disorder..$^{17,43,44}$ Hughes et $\mathrm{al}^{26}$ have demonstrated the relationships between extent of MMSE impairment and patterns of agraphia in AD. MMSE deficits in AD are linked to several comorbidity domains, including cardiovascular, ear, nose and throat, genitourinary, musculoskeletal/ integument, and neurologic.

We are not aware of studies that have examined the relationship between cognition and dysgraphia in DLB patients, nor of studies that have compared the cognitive impairment after writing between $\mathrm{AD}$ and DLB. Much of the current knowledge regarding the relationship between DLB and AD dementia and cognition is derived from clinical-pathological studies of atypical cases of dementia and specialty clinic samples. ${ }^{45,46}$ For instance clinic-based studies have shown that cortical Lewy body pathology is associated with more rapid decline in cognition; ;,47 however, this has not been noted in all studies. ${ }^{48,49}$

Cognitive fluctuations that occur in patients cannot be caused by sudden loss or gain of nerve cells; $;{ }^{50}$ recent evidence

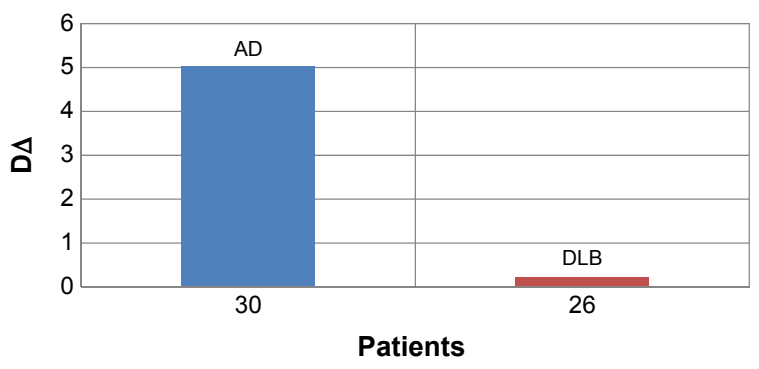

Figure 4 The difference $(\mathrm{D} \Delta)$ between cognitive performance in PQI and PQ2 by $A D$ patients and DLB patients expressed as $D \Delta$ means summated over all 10 days of testing.

Note: Values expressed as mean AD $>$ DLB.

Abbreviations: $A D$, Alzheimer's disease; DLB, dementia Lewy bodies; PQI, initial cognition test; PQ2, repeated cognition test. 


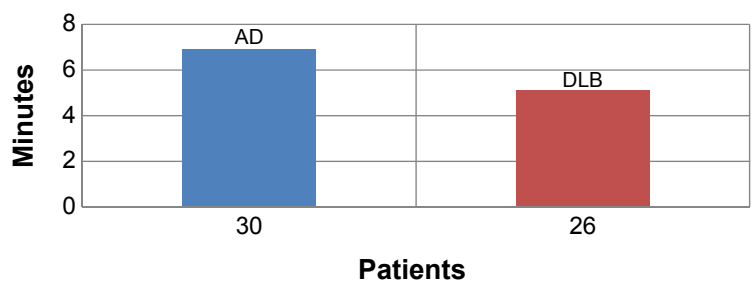

Figure 5 The amount of time spent writing clearly by AD patients and DLB patients expressed as means in the graphia test summated over all 12 days of testing. Note: Values expressed as mean DLB $<$ AD.

Abbreviations: AD, Alzheimer's disease; DLB, dementia Lewy bodies.

suggests that variations in the activity of neural networks, and the neural plasticity is mediated by morphological and functional modification of synapses, a process that depends on both synthesis and degradation of proteins, ${ }^{51}$ events targeting a variety of molecules in pre- and postsynaptic compartments. ${ }^{52}$

This study, by analyzing relationships between initial cognitive performance (PQ1), the deterioration in cognitive performance following a letter-writing task $(\mathrm{PQ} 1-\mathrm{PQ} 2=\mathrm{D} \Delta)$, and dysgraphia in AD and DLB patients, suggests that cognitive fluctuations that occur in patients with $\mathrm{AD}$ during the performance of handwritten scripts are not present in patients with DLB. During the observation period, the DLB patients have fluctuating confusion, inattention that is independent from the fatigue of the writing task.

May the differences noted in AD and DLB patients be due to the different speed at which the process of the protein degradation occurs? Is it the recovery of cognition in $\mathrm{AD}$ and DLB patients allowed to the influence of protein degradation in relation to temporal dynamics in other regions of the brain? The current study has a limitation: cognitive fluctuation was measured on majority of change in orientation, not other cognitive domains, approximately 20 minutes apart.

\section{Conclusion}

Our results can provide new insights into the mechanism of cognitive decline in AD and DLB patients and may be useful to develop a method based on dysgraphia in order to differentiate the diagnosis of both types of dementia. In particular, the writing, in association with the cognitive questionnaire, can be used as part of neuropsychological tests to diagnose the difference between AD and DLB.

\section{Disclosure}

The authors report no conflicts of interest in this work.

\section{References}

1. Fratiglioni L, Launer LJ, Andersen K, et al. Incidence of dementia and major subtypes in Europe: a collaborative study of population base cohorts. Neurologic Diseases in the Elderly Research Group. Neurology. 2000;54(11 Suppl 5):S10-S15.
2. Lobo A, Launer LJ, Fratiglioni L, et al. Prevalence of dementia and major subtypes in Europe: A collaborative study of population-based cohorts. Neurologic Diseases in the Elderly Research Group. Neurology. 2000;54(11 Suppl 5):S4-S9.

3. Tijms BM, Möller C, Vrenken H, et al. Single-subject grey matter graphs in Alzheimer's disease. PLoS One. 2013;8(3):e58921.

4. Ferri CP, Prince M, Brayne C, et al; Alzheimer's Disease International. Global prevalence of dementia: a Delphi consensus study. Lancet. 2005; 366(9503):2112-2117.

5. Ravaglia G, Forti P, De Ronchi D, et al. Prevalence and severity of dementia among northern Italian centenarians. Neurology. 1999;53(2): 416-418.

6. World Health Organization. Dementia a public health priority [webpage on the Internet]. Geneva: World Health Organization; 2012. Available from: http://www.who.int/mental_health/publications/ dementia_report_2012/en/.

7. Byrne EJ, Lennox G, Lowe J, Godwin-Austen RB. Diffuse Lewy body disease: clinical features in 15 cases. J Neurol Neurosurg Psychiatry. 1989;52(6):709-717.

8. McKeith IG, Galasko D, Kosaka K, et al. Consensus guidelines for the clinical and pathologic diagnosis of dementia with Lewy bodies (DLB): report of the consortium on DLB international workshop. Neurology. 1996;47(5):1113-1124.

9. Kolbeinsson H, Jónsson A. Delirium and dementia in acute medical admissions of elderly patients in Iceland. Acta Psychiatr Scand. 1993; 87(2):123-127.

10. Bradshaw J, Saling M, Hopwood M, Anderson V, Brodtmann A. Fluctuating cognition in dementia with Lewy bodies and Alzheimer's disease is qualitatively distinct. J Neurol Neurosurg Psychiatry. 2004; 75(3):382-387.

11. McKeith IG. Dementia with Lewy bodies. Br J Psychiatry. 2000;180: 144-147.

12. Lee DR, Taylor JP, Thomas AJ. Assessment of cognitive fluctuation in dementia: a systematic review of the literature. Int J Geriatr Psychiatry. 2012;27(10):989-998.

13. Horner J, Heyman A, Dawson D, Rogers H. The relationship of agraphia to the severity of dementia in Alzheimer's disease. Arch Neurol. 1988; 45(7):760-763.

14. LaBarge E, Smith DS, Dick L, Storandt M. Agraphia in dementia of the Alzheimer type. Arch Neurol. 1992;49(11):1151-1156.

15. Henderson VW, Buckwalter JG, Sobel E, Freed DM, Diz MM. The agraphia of Alzheimer's disease. Neurology. 1992:42(4):777-784.

16. Croisile B, Carmoi T, Adeleine P, Trillet M. Spelling in Alzheimer's disease. Behav Neurol. 1995;8:135-143.

17. Neils J, Roeltgen DP, Greer A. Spelling and attention in early Alzheimer's disease: evidence for impairment of the graphemic buffer. Brain Lang. 1995;49(3):241-262.

18. Roeltgen DP. Agraphia. In Heilman KM, Valenstein E, editors. Clinical Neuropsychology. 4th ed. New York, NY: Oxford University Press; 2003:126-145.

19. McKhann G, Drachman D, Folstein M, Katzman R, Price D, Stadlan EM. Clinical diagnosis of Alzheimer's disease: report of the NINCDS-ADRDA Work Group under the auspices of Department of Health and Human Services Task Force on Alzheimer's Disease. Neurology. 1984;34(7):939-944.

20. Ricci S, Fuso A, Ippoliti F, Businaro R. Stress-induced cytokines and neuronal dysfunction in Alzheimer's disease. J Alzheimers Dis. 2012; 28(1):11-24.

21. McKeith IG, Dickson DW, Lowe J, et al; Consortium on DLB. Diagnosis and management of dementia with Lewy bodies: third report of the DLB Consortium. Neurology. 2005;65(12):1863-1872.

22. Folstein MF, Folstein SE, McHugh PR. "Mini-mental state". A practical method for grading the cognitive state of patients for the clinician. J Psychiatr Res. 1975;12(3):189-198.

23. Martínez-Martin P, Gil-Nagel A, Gracia LM, Gómez JB, MartínezSarriés J, Bermejo F. Unified Parkinson's Disease Rating Scale characteristics and structure. The Cooperative Multicentric Group. Mov Disord. 1994;9(1):76-83. 
24. Walker MP, Ayre GA, Cummings JL, et al. The Clinician Assessment of Fluctuation and the One Day Fluctuation Assessment Scale. Two methods to assess fluctuating confusion in dementia. Br J Psychiatry. 2000;177:252-256.

25. Onofri E, Mercuri M, Salesi M, Ricciardi MR, Archer T, Ricci S. Cognitive performance deficits and dysgraphia in Alzheimer's disease patients. J Neurol Neurophysiol. 2014;5:223.

26. Hughes JC, Graham N, Patterson K, Hodges JR. Dysgraphia in mild dementia of Alzheimer's type. Neuropsychologia. 1997;35(4): 533-545.

27. Small JA, Sandhu N. Episodic and semantic memory influences on picture naming in Alzheimer's disease. Brain Lang. 2008;104(1):1-9.

28. Yasuda K, Nakamura T, Beckman B. Brain processing of proper names. Aphasiology. 2000;14(11):1067-1089.

29. Silveri MC, Corda F, Di Nardo M. Central and peripheral aspects of writing disorders in Alzheimer's disease. J Clin Exp Neuropsychol. 2007;29(2):179-186.

30. Croisile B, Ska B, Brabant MJ, et al. Comparative study of oral and written picture description in patients with Alzheimer's disease. Brain Lang. 1996;53(1):1-19.

31. Yoon JH, Suh MK, Jeong Y, et al. Agraphia in Korean patients with early onset Alzheimer's disease. Int Psychogeriatr. 2011;23(8): 1317-1326.

32. Pauc R, Young A. Little-known neurons of the medial wall: a literature review of pyramidal cells of the cingulate gyrus. J Chiropr Med. 2010; 9(3):115-120.

33. Allman JM, Hakeem A, Erwin JM, Nimchinsky E, Hof P. The anterior cingulate cortex. The evolution of an interface between emotion and cognition. Ann N Y Acad Sci. 2001;935:107-117.

34. Hayashi A, Nomura H, Mochizuki R, et al. Neural substrates for writing impairments in Japanese patients with mild Alzheimer's disease: a SPECT study. Neuropsychologia. 2011;49(7):1962-1968.

35. Sakurai Y, Mimura I, Mannen T. Agraphia for kanji resulting from a left posterior middle temporal gyrus lesion. Behav Neurol. 2008; 19(3):93-106.

36. Yaguchi H, Yaguchi M, Bando M. [A case of pure agraphia due to left parietal lobe infarction]. No To Shinkei. 2006;58(10):885-892. Japanese.

37. Tippett WJ, Sergio LE, Black SE. Compromised visually guided motor control in individuals with Alzheimer's disease: can reliable distinctions be observed? J Clin Neurosci. 2012;19(5):655-660.
38. Sitek EJ, Narozanska E, Barczak A, et al. Agraphia in patients with frontotemporal dementia and parkinsonism linked to chromosome 17 with P301L MAPT mutation: dysexecutive, aphasic, apraxic or spatial phenomenon? Neurocase. 2014;20(1):69-86.

39. Archer T, Kostrzewa RM. Staging neurological disorders: expressions of cognitive and motor disorder. Neurotox Res. 2010;18(2):107-111.

40. Lambert J, Giffard B, Nore F, de la Sayette V, Pasquier F, Eustache F. Central and peripheral agraphia in Alzheimer's disease: from the case of Auguste D. to a cognitive neuropsychology approach. Cortex. 2007;43(7): 935-951.

41. Bonnì S, Lupo F, Lo Gerfo E, et al. Altered parietal-motor connections in Alzheimer's disease patients. J Alzheimers Dis. 2013;33(2):525-533.

42. Terranova C, Carmen T, SantAngelo A, et al. Impairment of sensorymotor plasticity in mild Alzheimer's disease. Brain Stimul. 2013; 6(1):62-66.

43. Platel H, Lambert J, Eustache F, et al. Characteristics and evolution of writing impairment in Alzheimer's disease. Neuropsychologia. 1993;31(11):1147-1158.

44. Rapcsak SZ, Arthur SA, Bliklen DA, Rubens AB. Lexical agraphia in Alzheimer's disease. Arch Neurol. 1989;46(1):65-68.

45. Hansen L, Salmon D, Galasko D, et al. The Lewy body variant of Alzheimer's disease: a clinical and pathologic entity. Neurology. 1990;40(1):1-8.

46. Hamilton JM, Salmon DP, Galasko D, et al. Visuospatial deficits predict rate of cognitive decline in autopsy-verified dementia with Lewy bodies. Neuropsychology. 2008;22(6):729-737.

47. Galasko DR, Gould RL, Abramson IS, Salmon DP. Measuring cognitive change in a cohort of patients with Alzheimer's disease. Stat Med. 2000;19(11-12):1421-1432.

48. Hanyu H, Sato T, Hirao K, Kanetaka H, Sakurai H, Iwamoto T. Differences in clinical course between dementia with Lewy bodies and Alzheimer's disease. Eur J Neurol. 2009;16(2):212-217.

49. Walker Z, McKeith I, Rodda J, et al. Comparison of cognitive decline between dementia with Lewy bodies and Alzheimer's disease: a cohort study. BMJ Open. 2012;2:e000380.

50. Palop JJ, Chin J, Mucke L. A network dysfunction perspective on neurodegenerative diseases. Nature. 2006;443(7113):768-773.

51. Bingol B, Sheng M. Deconstruction for reconstruction: the role of proteolysis in neural plasticity and disease. Neuron. 2011;69(1):22-32.

52. Yi JJ, Ehlers MD. Emerging roles for ubiquitin and protein degradation in neuronal function. Pharmacol Rev. 2007;59(1):14-39.
Clinical Interventions in Aging

\section{Publish your work in this journal}

Clinical Interventions in Aging is an international, peer-reviewed journal focusing on evidence-based reports on the value or lack thereof of treatments intended to prevent or delay the onset of maladaptive correlates of aging in human beings. This journal is indexed on PubMed Central, MedLine,

\section{Dovepress}

CAS, Scopus and the Elsevier Bibliographic databases. The manuscript management system is completely online and includes a very quick and fair peer-review system, which is all easy to use. Visit http://www.dovepress. com/testimonials.php to read real quotes from published authors. 